Review

\title{
Ocular Toxoplasmosis: Mechanisms of Retinal Infection and Experimental Models
}

\author{
Veronica Rodriguez Fernandez ${ }^{1,2}$, Giovanni Casini ${ }^{3}\left[\right.$ and Fabrizio Bruschi an $^{1, *(\mathbb{D}}$ \\ 1 Department of Translational Research, School of Medicine, University of Pisa, 56126 Pisa, Italy; \\ veronica.rodriguezfernandez@uniroma1.it \\ 2 Department of Public Health and Infectious Disease Sapienza University, 00185 Rome, Italy \\ 3 Department of Biology, University of Pisa, 56126 Pisa, Italy; giovanni.casini@unipi.it \\ * Correspondence: fabrizio.bruschi@med.unipi.it
}

Citation: Rodriguez Fernandez, V.

Casini, G.; Bruschi, F. Ocular

Toxoplasmosis: Mechanisms of Retinal Infection and Experimental Models. Parasitologia 2021, 1, 50-60. https://doi.org/10.3390/

parasitologia1020007

Academic Editor: Geoff Hide

Received: 4 February 2021

Accepted: 12 April 2021

Published: 15 April 2021

Publisher's Note: MDPI stays neutral with regard to jurisdictional claims in published maps and institutional affiliations.

Copyright: () 2021 by the authors. Licensee MDPI, Basel, Switzerland. This article is an open access article distributed under the terms and conditions of the Creative Commons Attribution (CC BY) license (https:// creativecommons.org/licenses/by/ $4.0 /)$.

\begin{abstract}
Ocular toxoplasmosis (OT) is caused by the parasite Toxoplasma gondii and affects many individuals throughout the world. Infection may occur through congenital or acquired routes. The parasites enter the blood circulation and reach both the retina and the retinal pigment epithelium, where they may cause cell damage and cell death. Different routes of access are used by T. gondii to reach the retina through the retinal endothelium: by transmission inside leukocytes, as free parasites through a paracellular route, or after endothelial cell infection. A main feature of OT is the induction of an important inflammatory state, and the course of infection has been shown to be influenced by the host immunogenetics. On the other hand, there is evidence that the T. gondii phenotype also has an impact on the distribution of the pathology in different areas. Although considerable knowledge has been acquired on OT, a deeper knowledge of its mechanisms is necessary to provide new, more targeted treatment strategies. In particular, in addition to in vitro and in vivo experimental models, organotypic, ex vivo retinal explants may be useful in this direction.
\end{abstract}

Keywords: retina; inflammation; retinal infection; retinal models

\section{Introduction}

Ocular toxoplasmosis (OT) is an ocular disease caused by infection of the eye with the parasite Toxoplasma gondii and it is the most common cause of eye inflammation in the world. Its diagnosis is based on the detection in the patients of antibodies directed to parasite antigens or of parasite DNA [1]. A common feature reported by patients is blurred vision, and although the disease tends to resolve spontaneously, more serious, vision-threatening complications such as retinal detachment, choroidal neovascularization and glaucoma, may occur. Therefore, OT requires treatment to eliminate the parasite and the related inflammation [2]. Toxoplasma infection may take place through congenital or acquired routes. In the first case, the parasite present in an infected mother may cross the placenta and pass to her foetus. In the second, toxoplasmosis is acquired by eating raw or undercooked meat, vegetables or milk products, or by coming into contact with infected cat litter [3]. OT has been the subject of a considerable number of studies, and recent review papers have focused on specific aspects of the disease (see, for instance, [4]). However, deeper knowledge of the mechanisms of this pathology is necessary to provide new, more targeted treatment strategies. Here, we summarise the main features of ocular toxoplasmosis and indicate possible models for study of the disease.

\section{General Features of Toxoplasma gondii Infection}

Toxoplasma gondii, an obligate intracellular protozoan belonging to the phylum Apicomplexa, is characterised by a complex life cycle in which felines are the definitive hosts and other mammals, including humans, are intermediate hosts. In the intermediate hosts, 
the acute stage of the infection is characterised by tachyzoite proliferation, then the parasites form tissue cysts in various organs, including the brain, and establish a chronic infection [5].

The distribution of $T$. gondii is ubiquitous, and it is estimated that roughly 2 billion people are infected with the parasite at the global level, although the seroprevalence in industrialised countries has been declining for the last several years [6-9]. A positive correlation between humidity (which maintains oocyst viability) and Toxoplasma seroprevalence was observed in a survey carried out in 84 countries in different geographical areas [10]. In addition, a negative correlation has been reported between Toxoplasma seroprevalence and gross national product, or latitude, indicating that the parasite circulates better in the poorest populations in the southern hemisphere.

Infection may occur by ingestion of contaminated food or water (through oocysts), raw or undercooked meat (containing tissue cysts), vertically from mother to foetus, transfusion (both through tachyzoites), or transplantation of solid organ or bone marrow/stem cells (bradyzoites) [5]. The infection usually occurs asymptomatically, and when it is clinically manifest, the symptoms are negligible (in immunocompetent individuals), mimicking a flulike syndrome with a possible cervical lymphadenopathy, unless chorioretinitis occurs [5].

Both host factors (genetic background, gender, immunological status) and parasite factors (inoculum size, timing, genotype, virulence) may affect the course of infection in humans [5]. Gene sequencing studies have identified different genotypes (the classical I, II, III, as well as recombinant and exotic genotypes) of Toxoplasma with different clinical manifestations. Reinfection with genotypes other than those of a primary infection is also possible [11].

\section{Infection of the Human Retina}

Once T. gondii has established infection in the small intestine, tachyzoites enter the draining blood and lymph travelling to remote sites [12] as free bodies in the circulation, or inside leukocytes [13]. Different histopathological and clinical observations show that T. gondii tachyzoites enter the eye via the blood supply that reaches the retina through the choroidal vessels, which irrigate the photoreceptors located in the outer retina, or through the retinal vessels entering at the optic nerve head, which irrigate the inner retina $[14,15]$ (Figure 1).

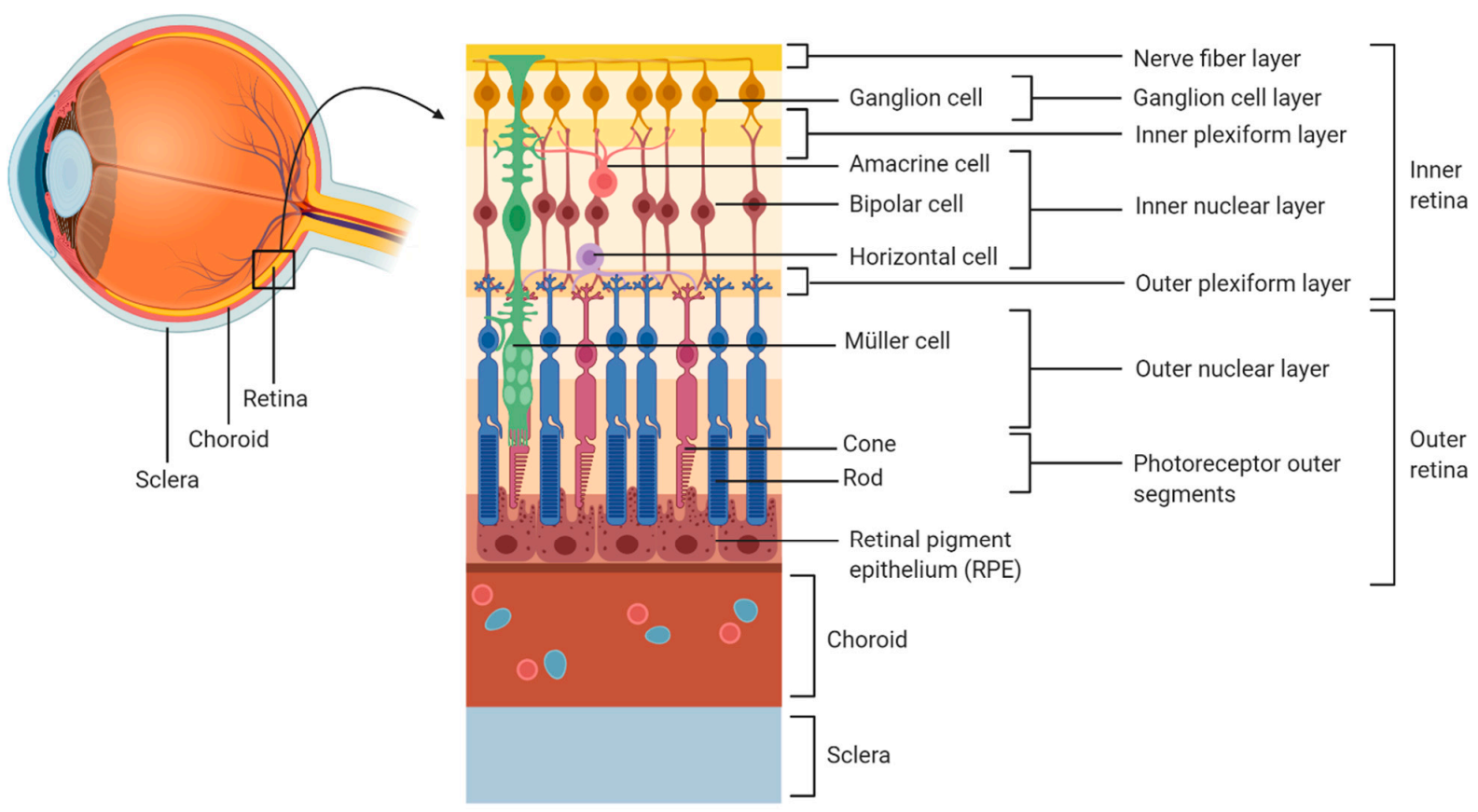

Figure 1. Organization of the human retina. Created with BioRender.com (https:/ /biorender.com/, accessed on 29 January 2021). 
During the early course of OT, necrosis has been reported in the nerve fibre layer and in the ganglion cell layer $[16,17]$. In addition, other studies have reported the presence of tachyzoites in the inner retina, especially in the proximity of retinal blood vessels $[18,19]$. This is in line with the development of retinal vasculitis in relation to OT. Indeed, during Toxoplasma infection in utero, the posterior pole of the eye is most typically involved. Therefore, since the development of the retinal vasculature begins from the posterior pole, retinal infection mediated by the blood vessels can expand only as far as the retinal vasculature has developed [20].

Three possible routes have been identified for the passage of tachyzoites across the retinal endothelium (Figure 2):

(a) Leukocyte transport.

(b) Free parasite through a paracellular route.

(c) Endothelial cell infection.

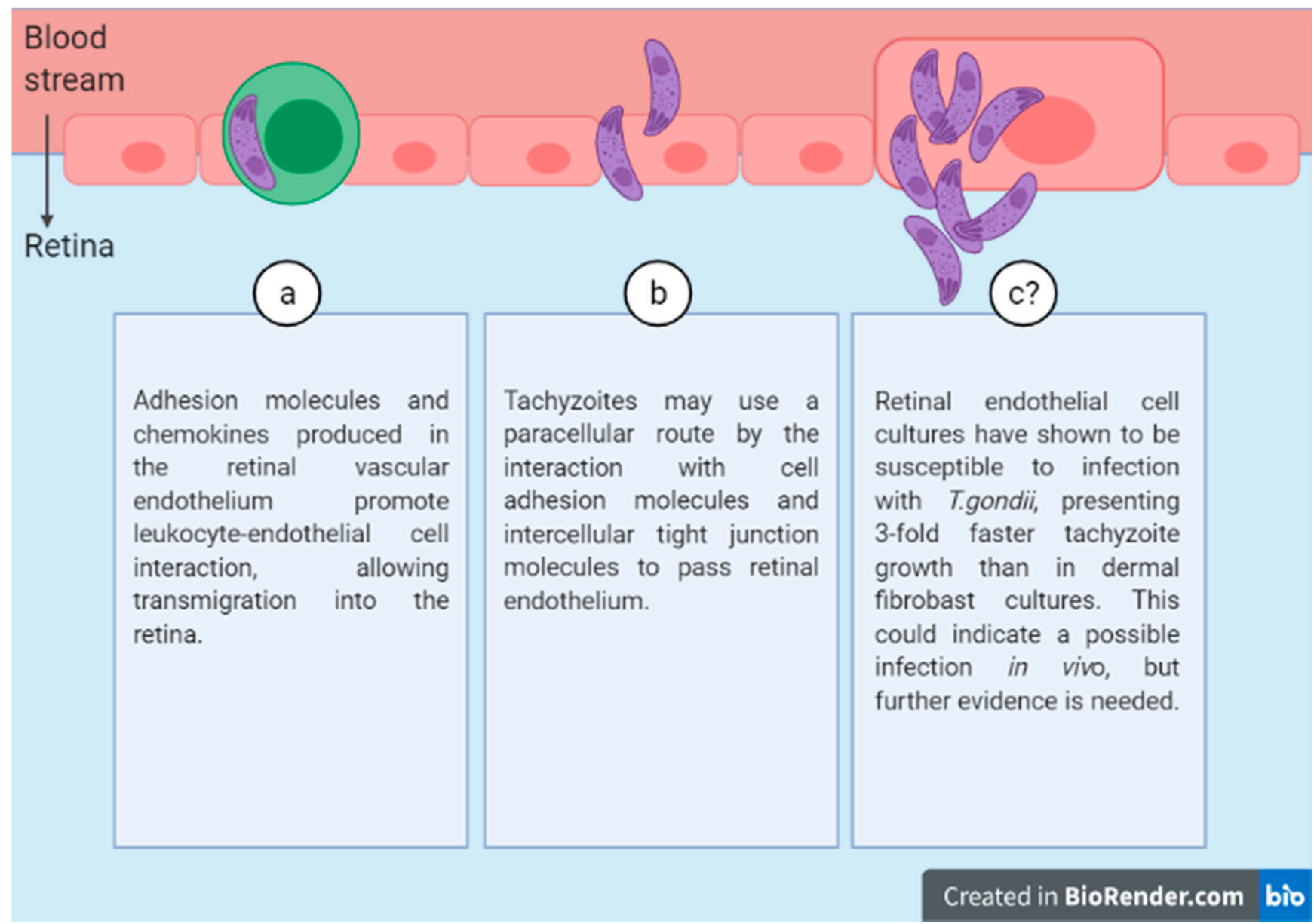

Figure 2. Three possible routes of T.gondii diffusion through the retinal endothelium. Created with BioRender.com (https://biorender. $\mathrm{com} /$, accessed on 29 January 2021).

\subsection{Leukocyte Transport}

It has been shown previously that monocytes are responsible for the arrival of $T$. gondii to the brain [21]. In addition, recent studies have shown that even though all dendritic cells (DCs) transmigrate through the retinal endothelium, those infected by T. gondii display hypermotililty and, therefore, better capacity to transmigrate compared to uninfected ones [22]. The infected DCs show an upregulation of Chemokine Receptor 7 (CCR7) that is not seen in uninfected DCs and is associated with the capacity of movement by chemotaxis [23]. 
Other leukocyte subpopulations, for instance monocyte-derived macrophages and neutrophils, can transport tachyzoites. However, when infected by the parasite neutrophils, they show a capacity for transmigrating in the gut epithelium but not in the retinal endothelium [23].

Leukocytes can pass through the retinal vascular endothelium at a slow speed. This process involves the production in the retinal vascular endothelium of adhesion molecules and chemokines that promote leukocyte-endothelial cell interaction. In particular, lectinlike adhesion glycoproteins (selectins) facilitate the rolling of leukocytes, while adhesion and transendothelial migration are mediated by the interaction of integrins (CD11/CD18, VLA-4), present in leukocytes, with immunoglobulin-like adhesion molecules, such as the intercellular adhesion molecule-1 (ICAM-1) or vascular cell adhesion molecule 1 (VCAM-1), expressed by endothelial cells [24]. Recent in vitro studies showed that infected leukocytes can release the tachyzoites while passing through the endothelium [25], suggesting that a similar mechanism may allow retinal invasion.

\subsection{Free Parasite through a Paracellular Route}

Tachyzoites may invade the retina using a paracellular route. This is suggested, for instance, by the results of an in vitro study in which tachyzoites were observed to pass from one chamber to another in a transwell through a membrane composed of human retinal endothelial cells. Differences in transmigration were observed depending on the virulence of the T. gondii strain [26]. The mechanism allowing tachyzoites to move through a paracellular route is likely to involve an interaction with cell adhesion and intercellular tight junction molecules. Indeed, T. gondii has been found to recognize ICAM-1 as a receptor in intestinal epithelial cells, and recently it has been shown that the blockade of this receptor reduces tachyzoite migration across a retinal endothelial monolayer [27]. In addition, tachyzoites may also use a transcellular route, replicating in the parasitophorous vacuole and then egressing the cell without affecting the barrier function of the retinal endothelium [28]. However, other studies show that, once tachyzoites are inside the cell, they may inhibit the phosphorylation of local adhesion kinase, thus compromising the tight junctions, and that parasite debris may increase barrier permeability [29]. In vitro results are controversial, and more research may help to elucidate the mechanisms underlying free tachyzoite migration into the retina.

\subsection{Endothelial Cell Infection}

Tachyzoites can remain infectious and survive outside host cells during long periods while maintaining the ability to adhere to the retinal endothelium [29].

Recent studies in which $T$. gondii tachyzoites were cultivated in different human endothelial cell lines (retinal, aortic, umbilical vein, and dermal microvasculature) showed that retinal endothelial cells were the most susceptible to infection, showing a tachyzoite growth rate three times faster than that of dermal fibroblasts [30]. This result suggests that in vivo tachyzoites may efficiently invade human retinal endothelial cells, especially because the human retinal endothelium has been observed to express high binding affinity for tachyzoites [31].

\subsection{Other Routes}

In few cases, tachyzoites might access the retina through the choroidal vasculature. To achieve this, the parasite must move across the outer blood-retinal barrier formed by the retinal pigment epithelium (RPE). In these cases, patients present multifocal greywhite lesions located in the outer retina and RPE [32]. Some in vitro studies showed that human monocytic THP-1 cells infected with T. gondii can transmigrate throughadult retinal pigment epithelial cells (ARPE)-19. The infected monocytes induce focal adhesion kinase signalling, resulting in disruption of tight junction proteins in the epithelium [33]. The junctional complexes are also disrupted, causing loss of barrier integrity, when ARPE-19 cells are infected with tachyzoites [34]. 


\section{Movement of $T$. gondii within the Human Retina}

In an isolated human eyecup preparation, tachyzoites were observed to migrate through the retinal layers. In particular, it was shown that some tachyzoites were concentrated in the inner retina and in the nerve fibre layer, while others were also found in the other retinal layers (inner plexiform, inner nuclear, outer plexiform and outer nuclear layers) [35]. This indicates that $T$. gondii tachyzoites can actively move through the human retina [35]. Other studies showed that this movement can be facilitated by leukocytes [36].

To identify the retinal cell types that are the preferred hosts of $T$. gondii, a study using dissociated human retinal cell cultures reported that the two major retinal cell populations, i.e., Müller glial cells and neurons, were the most susceptible [35]. In particular, the results showed a preference for Müller glial cells, which harboured a bulk of parasitophorous vacuoles and the highest parasite load. Moreover, parasite growth in these cells exceeded that in human dermal fibroblasts by over 50\% [4,34]. Other studies conducted in the brain showed a preference of $T$. gondii for astrocytes, but it is important to notice that, although Müller cells are specialized macroglial cells, they are phenotypically different from astrocytes and are absent in the brain [37].

Müller cells exert different biological functions in the retina, including establishment and maintenance of the blood-retina barrier, clearance of extracellular glutamate, release of antioxidants, electrolytic balance, and neuronal survival, among others [38]. They are also involved in immune responses. Indeed, a recent study shows that the parasite upregulates chemokine expression in infected Müller cells and, after leukocyte entry in the retina, some cell functions become activated while others are inhibited when leukocytes interact with infected Müller cells [39].

\section{Infection of the RPE by T. gondii}

Pigment epithelial cells in the retina constitute a barrier between the retina and the choroid. They also regulate the immune system by inhibiting leukocyte activity, which in some cases could induce inflammation and damage within the posterior segment of the eye [40].

Retinal hyperpigmentation is a very characteristic change during OT, mostly due to cell proliferation forming a multilaminar layering of the RPE. A recent study showed that this cell proliferation is due to an increase of Vascular Endothelial Growth Factor A (VEGFA) and Insulin-like Growth Factor 1 (IGF-1), along with a decrease in Thrombospondin 1 (TSP1) in infected cells [41,42]. Both VEGF-A and IGF-1 are proangiogenic proteins, while TSP1 is antiangiogenic $[43,44]$. Thus, infection in retinal pigment epithelial cells is expected to promote choroidal neovascularization. However, this is a rare situation during OT. Indeed, a recent study showed that the RPE produces Pigment Epithelial Derived Factor (PEDF) within hours of infection [4]. PEDF is an antiangiogenic factor, and its release at an early stage in the infection may prevent choroidal neovascularization [45].

\section{Immune Response during Retinal Infection}

The RPE upregulates the expression of major histocompatibility complex (MHC) class I and class II to present parasite antigens in the eye [46,47]. Tachyzoite-infected human RPE produces Granulocyte-Macrophage Colony-Stimulating Factor (GM-CSF), Interleukin 6 (IL-6), and IL-18, activating neutrophils and leading to the production of reactive oxygen species and inflammatory cytokines such as Tumour Necrosis Factor (TNF)- $\alpha$ and IL-1 $\beta$, which may trigger retinal damage associated to OT [48]. On the other hand, IL-6 has been reported to antagonize the activity of ocular Transforming Growth Factor $\beta$ (TGF- $\beta$, an anti-inflammatory cytokine), which would inhibit natural killer cell activity and Nitric Oxide production, allowing parasite survival [49].

Different studies have evaluated gene polymorphisms in the immune system that may influence the occurrence and manifestation of OT. Studies investigating the disease's association with the IL10-1082 A/G polymorphism showed that patients with OT are more likely to carry IL10-1082 A allele by approximately 2.5 -fold, which is associated with 
reduced IL-10 production [50]. This result is consistent with a lower capacity to control the inflammatory reaction during a general Toxoplasma infection. On the other hand, patients with a polymorphism that produces lower levels of IL-6 showed a more severe retinal inflammation in association with an increased parasite load [46].

The CT genotype and T allele of IL1A-889 C/T is associated with recurrence of retinitis in patients who had OT at least one year earlier. The $\mathrm{T}$ allele is associated with increased expression of IL-1 $\alpha$ [51], suggesting that the recurrence of OT is more likely in patients with intense inflammatory reactions. On the other hand, studies investigating TNF polymorphism did not show any association with OT [50].

The Human Leukocyte Antigen (HLA) is highly polymorphic and plays an essential role in the immune response. A recent study showed that HLA-B35 is a Class I HLA marker that predisposes to OT [52].

These results indicate that humans have a wide range of immune response-related genes with different polymorphisms, creating a particular risk profile with different pathogenetic mechanisms for each individual.

\section{Toxoplasma Genotype Influences the Course of Ocular Infection}

There are at least 16 haplogroups of $T$. gondii, grouped in six clades based on the singlenucleotid polymorphisms across the genome [53]. The most investigated types are I, II and III (haplogroups 1, 2 and 3). Other haplogroups with atypical or recombinant genetics are less well known, with little information in the literature [54]. Recent results from PCRbased studies on patients with toxoplasmosis show differences in genotype distribution among different countries (Table 1) [4]. In many cases there is a similar distribution of OT across countries, but there is only little information on African regions.

Table 1. Toxoplasma strain distribution [4].

\begin{tabular}{cc}
\hline T. gondii Genotype & Prevalent in \\
\hline Type I strain & United States, Poland, Spain, Brazil, Colombia and Egypt \\
\hline Type II strain & United States, Denmark, France, Germany, Spain and Portugal \\
\hline Type III strain & Greece \\
\hline Atypical strains & United States, French Guiana, Brazil and China \\
\hline
\end{tabular}

In the United States, Toxoplasma strain type has been identified as an important factor that determines the severity of congenital toxoplasmosis [55]. Different recombinant (atypical) strains, such as Type $x$ (haplogroup 12), are associated with severe disease in patients with AIDS and OT in North, Central and South America [56,57]. In Europe, Type II strain accounts for $70-80 \%$ of human infections [57]. In immunocompromised individuals with OT, genotype II accounts for $85 \%$ of the cases [58]. Among Toxoplasma-infected German uveitis patients with OT, a novel nonreactive serotype in $44 \%$ of cases, and Type II in $41 \%$ of cases, were observed [59].

To understand the relationship between OT and parasite genetics, recent studies where mice were infected with type I, type II or two types from haplogroup 6 strains, showed that all of these strains can induce OT [46,47]. The road to understanding the differences in virulence is still ahead, and more studies might be useful to shed light on the pathogenesis of the different strains.

\section{Models to Study T. gondii Retinal Infection}

Although the data reported above constitute an important body of both experimental and clinical data characterizing ocular toxoplasmosis, there is still the need for further information to develop efficacious treatments. For instance, little is known of the reaction to infection of specific cellular types of the retina, or whether different retinal cell types display different sensitivities to infection. In addition, to our knowledge, no information is available on the molecular mechanisms leading to cell damage or cell death. Furthermore, new 
models are necessary to test possible treatment options (for instance with anti-inflammatory or antioxidant compounds) in a fast and reliable manner. Finally, models are needed which could be easily manipulated, for instance, to modify different parameters of the infection or to induce or retard infection reactivation.

Most experimental models used to date consist of in vitro preparations, also including human retinal cell subsets, or laboratory mice. In vivo experimental models involve local or systemic inoculation of parasites to induce acute disease, or sequential systemic and local parasite inoculations to trigger recurrent disease. An almost unexplored possibility is the use of organotypic, ex vivo retinal explants, which offer the advantage of easy manipulation and fast and reliable observation of the effects of exogenous compounds while maintaining the complexity and the extracellular environment typical of the in vivo setting.

\subsection{In Vitro Models}

In vitro models are used to study factors that influence parasite growth and infection capabilities, as well as the response of host cell types to infection with different $T$. gondii strains. There are two different models: the RPE model, which is used to study the immunopathogenesis of infection, and the retinal endothelium, which mimics the biological barrier between blood and retina, allowing to study how the parasite enters the blood-retina barrier [60].

\subsection{In Vivo Models}

Some features are important to consider when using animal models, including parasite strain and/or stage, inoculum size and infection route. A recent review summarized these models [60]. The first animal model to study OT was established by Hogan in 1951 using rabbits, while Frenkel induced OT via intraperitoneal infection of hamsters in 1953. Many other animals have been investigated as experimental models for OT, but in recent years mice have become the model of choice, and nowadays there is a wide variety of murine models to study OT that use congenital, intraocular or intraperitoneal infection. Mice constitute the preferred model because they are accessible, their genome is completely sequenced and there is a large variety of knock-out mice. The only drawback is that the anatomy of the eye is different from that of humans since mice lack a macula, but otherwise OT in mice successfully mimics the main hallmarks of the disease in humans, such as retinochoroidal lesions, cellular inflammation, and vasculitis [61].

Intraperitoneal infection is the most common route of infection in models of OT because it is easy to perform and leads to OT in hamsters and mice [62]. However, it does not represent the natural route of infection in humans. Other routes are also used, such as intraocular injection in primates, guinea pigs, rabbits and mice. This route may cause side effects, interfering with the course of disease, therefore it is preferred to position the parasites on the surface of the eye [63]. Intracarotid injection has been used in rabbits and cats, but it is difficult to perform in small animals and does not represent the natural route of infection in humans [60]. The peroral route is rarely chosen because it causes a delayed infection as compared with the intraperitoneal infection [61].

\subsection{Ex Vivo Models}

Retinal explant cultures have been widely used to examine different biological processes (Figure 3). This system mimics the functional dynamics of the organ, overcoming cell culture and becoming a middle point between in vitro cell cultures and in vivo animal models. Besides these advantages, obvious limitations characterize the ex vivo organotypic explants, which are time-limited and independent of the systemic host immune response. 
a. IN VIVO

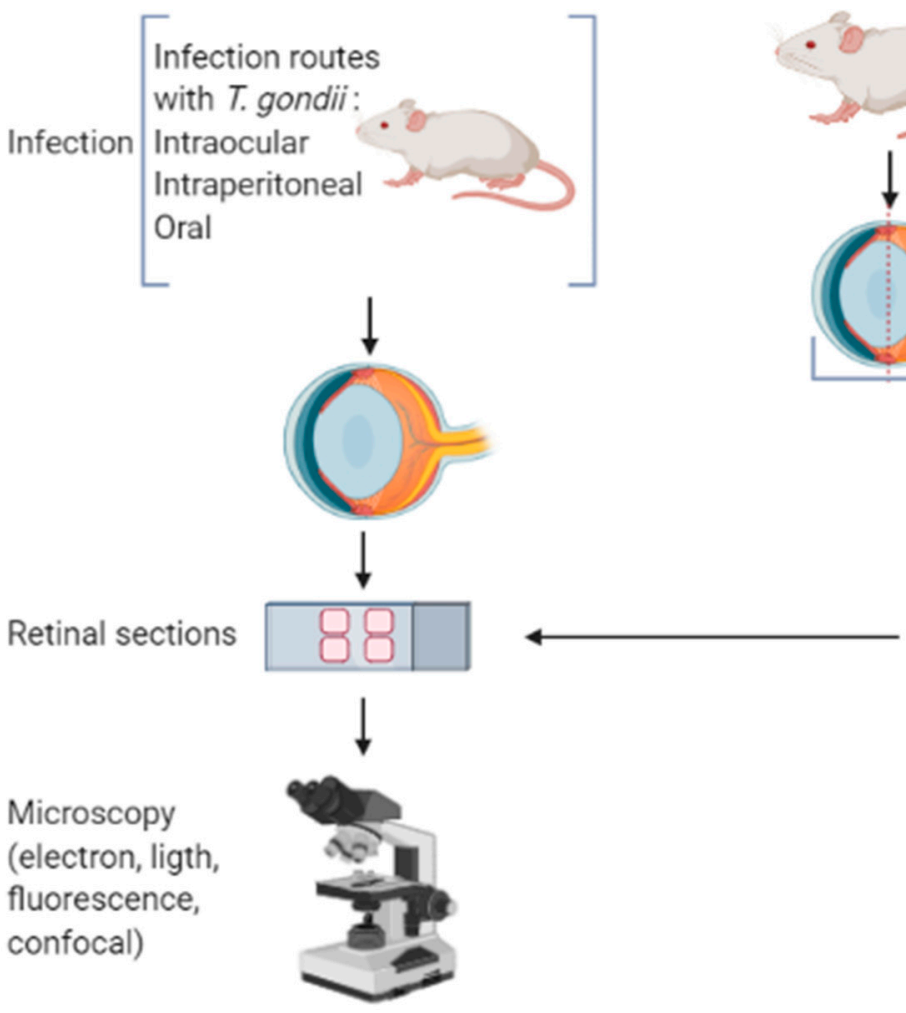

b. EX VIVO
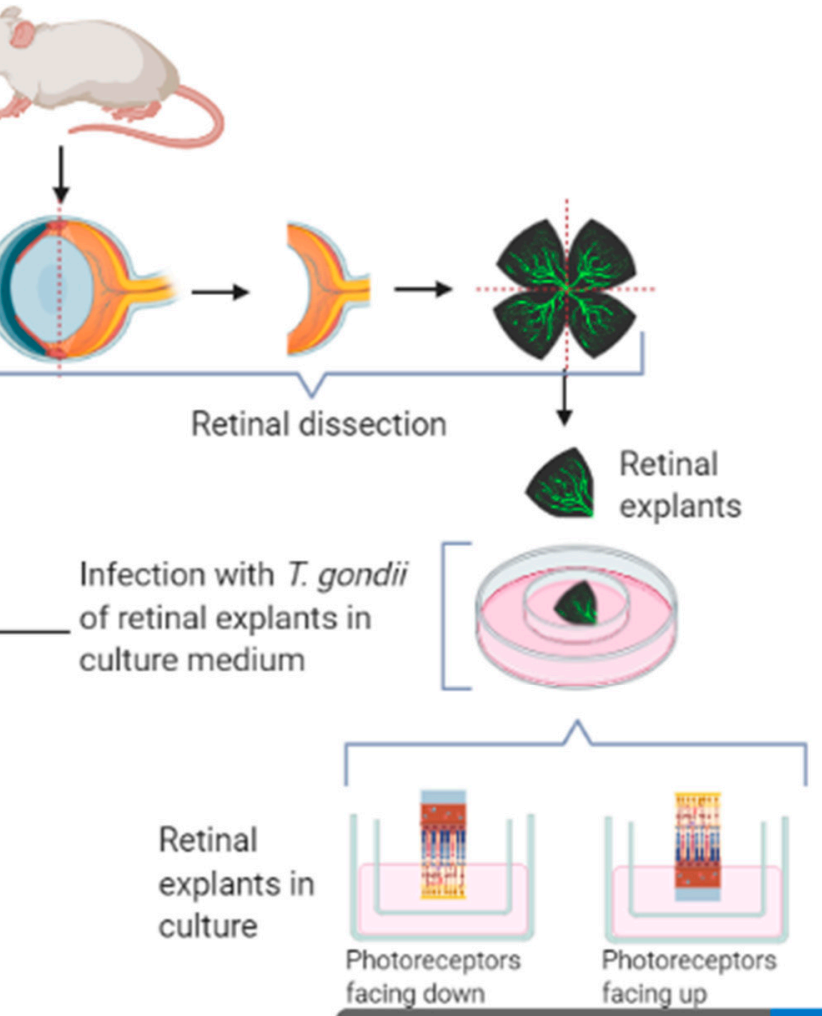

Created in BioRender.com bio

Figure 3. In vivo (a) and ex vivo (b) models to study Toxoplasma infection in the retina. For the in vivo infection, T. gondii is inoculated via intraocular, intraperitoneal or oral route. The ex vivo model uses retinal explants infected and maintained in culture. In both cases retinal sections are prepared from fixed tissue and observed with different types of microscopy. Created with BioRender.com (https:/ / biorender.com/, accessed on 29 January 2021).

The first retinal explants were maintained on plasma clots by Strangeways et al. in 1926 [64]. Since then, a wide range of animal retinal explants have been successfully maintained, including those from zebrafish, goldfish, rats, mice, ferrets, hamsters, guinea pigs, rabbits, cats, dogs, pigs, cows and primates. These models have overcome the disadvantages of in vitro cultures, allowing the study of different tissue mechanisms. Some human retinas from cadaveric donors have also been used to prepare retinal explants [64], but this option is not easily available and, therefore, is less commonly used.

Several methods are used for culturing retinal explants, but the one where the retina is placed with photoreceptor layer facing downward on rafts of nitrocellulose filters is the most used [65,66]. Adult murine retinas (from 4-5 to more than 12 weeks old) have been maintained in culture for up to 10 days, after which degeneration of neuronal and glial cells occur $[66,67]$. During this time, it is possible to study OT during early infection and the cell populations preferred by Toxoplasma within the retina, as well as the parasite migration in the tissue.

\section{Conclusions}

Even though Toxoplasma is a well-studied parasite, the mechanisms behind human OT are still far from being elucidated. So far, it has been shown that the parasite might have different strategies to successfully persist in the host, entering the retina by at least three different routes. Then, the tachyzoites migrate across the retinal layers, spreading the infection within the inner retina. However, there is still work ahead to identify the cells most affected and to gain more knowledge about the immune response. New ex vivo 
models to study OT will surely help answering these and other questions that might occur on the way towards a better understanding of $T$. gondii infection of the retina.

Author Contributions: Conceptualization, V.R.F. and F.B.; methodology, F.B. and G.C.; software, V.R.F.; validation, F.B. and G.C.; formal analysis, F.B. and G.C.; investigation, V.R.F.; resources, F.B. and G.C.; data curation, V.R.F.; writing-original draft preparation, V.R.F.; writing-review and editing, F.B. and G.C.; visualization, F.B.; supervision, F.B. and G.C.; project administration, F.B. All authors have read and agreed to the published version of the manuscript.

Funding: This research received no external funding.

Institutional Review Board Statement: Not applicable.

Informed Consent Statement: Not applicable.

Data Availability Statement: Data is contained within the article.

Conflicts of Interest: The authors declare no conflict of interest.

\section{References}

1. Liu, Q.; Wang, Z.-D.; Huang, S.-Y.; Zhu, X.-Q. Diagnosis of Toxoplasmosis and Typing of Toxoplasma gondii. Parasit Vectors 2015, 8. [CrossRef] [PubMed]

2. Park, Y.-H.; Nam, H.-W. Clinical Features and Treatment of Ocular Toxoplasmosis. Korean J. Parasitol. 2013, 51, 393-399. [CrossRef] [PubMed]

3. Hussain, M.A.; Stitt, V.; Szabo, E.A.; Nelan, B. Toxoplasma gondii in the Food Supply. Pathogens 2017, 6, 21. [CrossRef]

4. Smith, J.R.; Ashander, L.M.; Arruda, S.L.; Cordeiro, C.A.; Lie, S.; Rochet, E.; Belfort, R.; Furtado, J.M. Pathogenesis of Ocular Toxoplasmosis. Prog. Retin. Eye Res. 2020, 100882. [CrossRef] [PubMed]

5. Montoya, J.G.; Liesenfeld, O. Toxoplasmosis. Lancet 2004, 363, 1965-1976. [CrossRef]

6. Jones, J.L.; Kruszon-Moran, D.; Wilson, M.; McQuillan, G.; Navin, T.; McAuley, J.B. Toxoplasma gondii Infection in the United States: Seroprevalence and Risk Factors. Am. J. Epidemiol. 2001, 154, 357-365. [CrossRef]

7. Hofhuis, A.; van Pelt, W.; van Duynhoven, Y.T.H.P.; Nijhuis, C.D.M.; Mollema, L.; van der Klis, F.R.M.; Havelaar, A.H.; Kortbeek, L.M. Decreased Prevalence and Age-Specific Risk Factors for Toxoplasma gondii IgG Antibodies in The Netherlands between 1995/1996 and 2006/2007. Epidemiol. Infect. 2011, 139, 530-538. [CrossRef]

8. Pinto, B.; Castagna, B.; Mattei, R.; Bruzzi, R.; Chiumiento, L.; Cristofani, R.; Buffolano, W.; Bruschi, F. Seroprevalence for Toxoplasmosis in Individuals Living in North West Tuscany: Access to Toxo-Test in Central Italy. Eur. J. Clin. Microbiol. Infect. Dis. 2012, 31, 1151-1156. [CrossRef]

9. Mosti, M.; Pinto, B.; Giromella, A.; Fabiani, S.; Cristofani, R.; Panichi, M.; Bruschi, F. A 4-Year Evaluation of Toxoplasmosis Seroprevalence in the General Population and in Women of Reproductive Age in Central Italy. Epidemiol. Infect. 2013, 141, 2192-2195. [CrossRef]

10. Flegr, J.; Prandota, J.; Sovičková, M.; Israili, Z.H. Toxoplasmosis-A Global Threat. Correlation of Latent Toxoplasmosis with Specific Disease Burden in a Set of 88 Countries. PLoS ONE 2014, 9, e90203. [CrossRef]

11. Boothroyd, J.C.; Grigg, M.E. Population Biology of Toxoplasma gondii and Its Relevance to Human Infection: Do Different Strains Cause Different Disease? Curr. Opin. Microbiol. 2002, 5, 438-442. [CrossRef]

12. Dubey, J.P. Toxoplasmosis of Animals and Humans; CRC Press: Boca Raton, FL, USA, 2016. [CrossRef]

13. Silveira, C.; Vallochi, A.; Silva, U.; Muccioli, C.; Holland, G.; Nussenblatt, R.; Belfort, R.; Rizzo, L. Toxoplasma gondii in the Peripheral Blood of Patients with Acute and Chronic Toxoplasmosis. Br. J. Ophthalmol. 2011, 95, 396-400. [CrossRef]

14. Hildebrand, G.D.; Fielder, A.R. Anatomy and Physiology of the Retina. In Pediatric Retina; Reynolds, J., Olitsky, S., Eds.; Springer: Berlin/Heidelberg, Germany, 2011; pp. 39-65. [CrossRef]

15. Feustel, S.M.; Meissner, M.; Liesenfeld, O. Toxoplasma gondii and the Blood-Brain Barrier. Virulence 2012, 3, 182-192. [CrossRef] [PubMed]

16. Nicholson, D.H.; Wolchok, E.B. Ocular Toxoplasmosis in an Adult Receiving Long-Term Corticosteroid Therapy. Arch. Ophthalmol. 1976, 94, 248-254. [CrossRef] [PubMed]

17. Yeo, J.H.; Jakobiec, F.A.; Iwamoto, T.; Richard, G.; Kreissig, I. Opportunistic Toxoplasmic Retinochoroiditis Following Chemotherapy for Systemic Lymphoma. A Light and Electron Microscopic Study. Ophthalmology 1983, 90, 885-898. [CrossRef]

18. Holland, G.N.; Engstrom, R.E.; Glasgow, B.J.; Berger, B.B.; Daniels, S.A.; Sidikaro, Y.; Harmon, J.A.; Fischer, D.H.; Boyer, D.S.; Rao, N.A. Ocular Toxoplasmosis in Patients with the Acquired Immunodeficiency Syndrome. Am. J. Ophthalmol. 1988, 106, 653-667. [CrossRef]

19. Roberts, F.; Mets, M.B.; Ferguson, D.J.; O'Grady, R.; O'Grady, C.; Thulliez, P.; Brézin, A.P.; McLeod, R. Histopathological Features of Ocular Toxoplasmosis in the Fetus and Infant. Arch. Ophthalmol. 2001, 119, 51-58.

20. Provis, J.M. Development of the Primate Retinal Vasculature. Prog. Retin. Eye Res. 2001, 20, 799-821. [CrossRef] 
21. Courret, N.; Darche, S.; Sonigo, P.; Milon, G.; Buzoni-Gâtel, D.; Tardieux, I. CD11c- and CD11b-Expressing Mouse Leukocytes Transport Single Toxoplasma gondii Tachyzoites to the Brain. Blood 2006, 107, 309-316. [CrossRef] [PubMed]

22. Lambert, H.; Hitziger, N.; Dellacasa, I.; Svensson, M.; Barragan, A. Induction of Dendritic Cell Migration upon Toxoplasma gondii Infection Potentiates Parasite Dissemination. Cell. Microbiol. 2006, 8, 1611-1623. [CrossRef] [PubMed]

23. Weidner, J.M.; Kanatani, S.; Hernández-Castañeda, M.A.; Fuks, J.M.; Rethi, B.; Wallin, R.P.A.; Barragan, A. Rapid Cytoskeleton Remodelling in Dendritic Cells Following Invasion by Toxoplasma gondii Coincides with the Onset of a Hypermigratory Phenotype. Cell. Microbiol. 2013, 15, 1735-1752. [CrossRef] [PubMed]

24. Granger, D.N.; Senchenkova, E. Leukocyte-Endothelial Cell Adhesion; Morgan \& Claypool Life Sciences: San Rafael, CA, USA, 2010.

25. Baba, M.; Batanova, T.; Kitoh, K.; Takashima, Y. Adhesion of Toxoplasma gondii Tachyzoite-Infected Vehicle Leukocytes to Capillary Endothelial Cells Triggers Timely Parasite Egression. Sci. Rep. 2017, 7, 5675. [CrossRef] [PubMed]

26. Ashander, L.M.; Lie, S.; Ma, Y.; Rochet, E.; Washington, J.M.; Furtado, J.M.; Appukuttan, B.; Smith, J.R. Neutrophil Activities in Human Ocular Toxoplasmosis: An In Vitro Study with Human Cells. Investig. Ophthalmol. Vis. Sci. 2019, 60, 4652-4660. [CrossRef] [PubMed]

27. Furtado, J.M.; Bharadwaj, A.S.; Ashander, L.M.; Olivas, A.; Smith, J.R. Migration of Toxoplasma gondii-Infected Dendritic Cells across Human Retinal Vascular Endothelium. Investig. Ophthalmol. Vis. Sci. 2012, 53, 6856-6862. [CrossRef] [PubMed]

28. Smith, J.R.; Franc, D.T.; Carter, N.S.; Zamora, D.; Planck, S.R.; Rosenbaum, J.T. Susceptibility of retinal vascular endothelium to infection with Toxoplasma gondii tachyzoites. Investig. Ophthalmol. Vis. Sci. 2004, 45, 1157-1161. [CrossRef]

29. Konradt, C.; Ueno, N.; Christian, D.A.; Delong, J.H.; Pritchard, G.H.; Herz, J.; Bzik, D.J.; Koshy, A.A.; McGavern, D.B.; Lodoen, M.B.; et al. Endothelial Cells Are a Replicative Niche for Entry of Toxoplasma gondii to the Central Nervous System. Nat. Microbiol. 2016, 1, 16001. [CrossRef] [PubMed]

30. Furtado, J.M.; Bharadwaj, A.S.; Chipps, T.J.; Pan, Y.; Ashander, L.M.; Smith, J.R. Toxoplasma gondii tachyzoites cross retinal endothelium assisted by intercellular adhesion molecule-1 in vitro. Immunol. Cell Biol. 2012, 90, 912-915. [CrossRef] [PubMed]

31. Smith, J.R.; David, L.L.; Appukuttan, B.; Wilmarth, P.A. Angiogenic and Immunologic Proteins Identified by Deep Proteomic Profiling of Human Retinal and Choroidal Vascular Endothelial Cells: Potential Targets for New Biologic Drugs. Am. J. Ophthalmol. 2018, 193, 197-229. [CrossRef]

32. Hegde, S.; Relhan, N.; Pathengay, A.; Bawdekar, A.; Choudhury, H.; Jindal, A.; Flynn, H.W., Jr. Coexisting choroidal neovascularization and active retinochoroiditis-an uncommon presentation of ocular toxoplasmosis. J. Ophthalmic. Inflamm. Infect. $2015,5,22$. [CrossRef] [PubMed]

33. Song, H.; Jun, H.; Kim, J.; Lee, Y.-H.; Choi, M.-H.; Kim, J. Disruption of Outer Blood-Retinal Barrier by Toxoplasma gondii-Infected Monocytes Is Mediated by Paracrinely Activated FAK Signaling. PLoS ONE 2017, 12. [CrossRef] [PubMed]

34. Nogueira, A.R.; Leve, F.; Morgado-Diaz, J.; Tedesco, R.C.; Pereira, M.C.S. Effect of Toxoplasma gondii Infection on the Junctional Complex of Retinal Pigment Epithelial Cells. Parasitology 2016, 143, 568-575. [CrossRef]

35. Furtado, J.M.; Ashander, L.M.; Mohs, K.; Chipps, T.J.; Appukuttan, B.; Smith, J.R. Toxoplasma gondii Migration within and Infection of Human Retina. PLoS ONE 2013, 8, e54358. [CrossRef]

36. Drewry, L.L.; Jones, N.G.; Wang, Q.; Onken, M.D.; Miller, M.J.; Sibley, L.D. The Secreted Kinase ROP17 Promotes Toxoplasma gondii Dissemination by Hijacking Monocyte Tissue Migration. Nat. Microbiol. 2019, 4, 1951-1963. [CrossRef]

37. Reichenbach, A.; Bringmann, A. Glia of the Human Retina. Glia 2019, 68. [CrossRef] [PubMed]

38. Devoldere, J.; Peynshaert, K.; De Smedt, S.C.; Remaut, K. Müller cells as a target for retinal therapy. Drug Discov. Today 2019, 24, 1483-1498. [CrossRef] [PubMed]

39. Knight, B.C.; Kissane, S.; Falciani, F.; Salmon, M.; Stanford, M.R.; Wallace, G.R. Expression Analysis of Immune Response Genes of Müller Cells Infected with Toxoplasma gondii. J. Neuroimmunol. 2006, 179, 126-131. [CrossRef] [PubMed]

40. Mochizuki, M.; Sugita, S.; Kamoi, K. Immunological Homeostasis of the Eye. Prog. Retin. Eye Res. 2013, 33, 10-27. [CrossRef]

41. Lie, S.; Vieira, B.R.; Arruda, S.; Simões, M.; Ashander, L.M.; Furtado, J.M.; Smith, J.R. Molecular Basis of The Retinal Pigment Epithelial Changes That Characterize the Ocular Lesion in Toxoplasmosis. Microorganisms 2019, 7, 405. [CrossRef] [PubMed]

42. Armstrong, L.C.; Björkblom, B.; Hankenson, K.D.; Siadak, A.W.; Stiles, C.E.; Bornstein, P. Thrombospondin 2 Inhibits Microvascular Endothelial Cell Proliferation by a Caspase-Independent Mechanism. Mol. Biol. Cell 2002, 13, 1893-1905. [CrossRef]

43. Lawler, P.R.; Lawler, J. Molecular Basis for the Regulation of Angiogenesis by Thrombospondin-1 and -2. Cold Spring Harb. Perspect. Med. 2012, 2. [CrossRef] [PubMed]

44. Bach, L.A. Endothelial Cells and the IGF System. J. Mol. Endocrinol. 2015, 54, R1-R13. [CrossRef]

45. Zhang, S.X.; Ma, J. Ocular Neovascularization: Implication of Endogenous Angiogenic Inhibitors and Potential Therapy. Prog. Retin. Eye Res. 2007, 26, 1-37. [CrossRef]

46. Lyons, R.E.; Anthony, J.P.; Ferguson, D.J.P.; Byrne, N.; Alexander, J.; Roberts, F.; Roberts, C.W. Immunological Studies of Chronic Ocular Toxoplasmosis: Up-Regulation of Major Histocompatibility Complex Class I and Transforming Growth Factor $\beta$ and a Protective Role for Interleukin-6. Infect. Immun. 2001, 69, 2589-2595. [CrossRef] [PubMed]

47. Osusky, R.; Dorio, R.J.; Arora, Y.K.; Ryan, S.J.; Walker, S.M. MHC Class II Positive Retinal Pigment Epithelial(RPE) Cells Can Function as Antigen-Presenting Cells for Microbial Superantigen. Ocul. Immunol. Inflamm. 1997, 5, 43-50. [CrossRef] [PubMed]

48. Nagineni, C.N.; Detrick, B.; Hooks, J.J. Toxoplasma gondii Infection Induces Gene Expression and Secretion of Interleukin 1(IL-1), IL-6, Granulocyte-Macrophage Colony-Stimulating Factor, and Intercellular Adhesion Molecule 1 by Human Retinal Pigment Epithelial Cells. Infect. Immun. 2000, 68, 407-410. [CrossRef] [PubMed] 
49. Ohta, K.; Yamagami, S.; Taylor, A.W.; Streilein, J.W. IL-6 Antagonizes TGF- $\beta$ and Abolishes Immune Privilege in Eyes with Endotoxin-Induced Uveitis. Investig. Ophthalmol. Vis. Sci. 2000, 41, 2591-2599.

50. Naranjo-Galvis, C.; de-la-Torre, A.; Mantilla, E.; Beltrán-Angarita, L.; Elcoroaristizabal-Martín, X.; Mcleod, R.; AllieyRodriguez, N.; Begeman, I.; Melo, C.; Gomez-Marin, J.; et al. Genetic Polymorphisms in Cytokine Genes in Colombian Patients with Ocular Toxoplasmosis. Infect. Immun. 2018, 86, IAI.00597-17. [CrossRef] [PubMed]

51. Shirodaria, S.; Smith, J.; Mckay, I.; Kennett, C.N.; Hughes, F. Polymorphisms in the IL-1A Gene Are Correlated with Levels of Interleukin-1 Protein in Gingival Crevicular Fluid of Teeth with Severe Periodontal Disease. J. Dent. Res. 2000, 79, 1864-1869. [CrossRef] [PubMed]

52. Demarco, A.; Rodrigues, M.; Figueiredo, J.; Deghaide, N.; Menezes, M.; Demarco, L.; Fernandes, A.; Donadi, E. Susceptibility to Toxoplasmic Retinochoroiditis Is Associated with Hla Alleles Reported to Be Implicated with Rapid Progression to Aids. Dis. Markers 2012, 33, 309-312. [CrossRef]

53. Behnke, M.S.; Dubey, J.P.; Sibley, L.D. Genetic Mapping of Pathogenesis Determinants in Toxoplasma gondii. Annu. Rev. Microbiol. 2016, 70, 63-81. [CrossRef]

54. Su, C.; Dubey, J.P. Isolation and Genotyping of Toxoplasma gondii Strains. Methods Mol. Biol. 2020, 2071, 49-80. [CrossRef]

55. McLeod, R.; Boyer, K.M.; Lee, D.; Mui, E.; Wroblewski, K.; Karrison, T.; Noble, A.G.; Withers, S.; Swisher, C.N.; Heydemann, P.T.; et al. Toxoplasmosis Study Group. Prematurity and Severity Are Associated with Toxoplasma gondii Alleles (NCCCTS, 1981-2009). Clin. Infect. Dis. 2012, 54, 1595-1605. [CrossRef] [PubMed]

56. Khan, A.; Jordan, C.; Muccioli, C.; Vallochi, A.L.; Rizzo, L.V.; Belfort, R.; Vitor, R.W.A.; Silveira, C.; Sibley, L.D. Genetic Divergence of Toxoplasma gondii Strains Associated with Ocular Toxoplasmosis, Brazil. Emerg. Infect. Dis. 2006, 12, 942-949. [CrossRef] [PubMed]

57. Lehmann, T.; Marcet, P.L.; Graham, D.H.; Dahl, E.R.; Dubey, J.P. Globalization and the Population Structure of Toxoplasma gondii. Proc. Natl. Acad. Sci. USA 2006, 103, 11423-11428. [CrossRef]

58. Fekkar, A.; Ajzenberg, D.; Bodaghi, B.; Touafek, F.; Le Hoang, P.; Delmas, J.; Robert, P.Y.; Dardé, M.L.; Mazier, D.; Paris, L. Direct Genotyping of Toxoplasma gondii in Ocular Fluid Samples from 20 Patients with Ocular Toxoplasmosis: Predominance of Type II in France. J. Clin. Microbiol. 2011, 49, 1513-1517. [CrossRef] [PubMed]

59. Shobab, L.; Pleyer, U.; Johnsen, J.; Metzner, S.; James, E.R.; Torun, N.; Fay, M.P.; Liesenfeld, O.; Grigg, M.E. Toxoplasma Serotype Is Associated with Development of Ocular Toxoplasmosis. J. Infect. Dis. 2013, 208, 1520-1528. [CrossRef] [PubMed]

60. Dukaczewska, A.; Tedesco, R.; Liesenfeld, O. Experimental Models of Ocular Infection with Toxoplasma gondii. Eur. J. Microbiol. Immunol. 2015, 5, 293-305. [CrossRef] [PubMed]

61. Calabrese, K.S.; Tedesco, R.C.; Zaverucha do Valle, T.; Barbosa, H.S. Serum and Aqueous Humour Cytokine Response and Histopathological Alterations during Ocular Toxoplasma gondii Infection in C57BL/6 Mice. Micron 2008, 39, $1335-1341$. [CrossRef] [PubMed]

62. Frenkel, J.K. Ocular Lesions in Hamsters*: With Chronic Toxoplasma and Besnoitia Infection. Am. J. Ophthalmol. 1955, 39 Pt 2, 203-225. [CrossRef]

63. Tedesco, R.C.; Smith, R.L.; Corte-Real, S.; Calabrese, K.S. Ocular Toxoplasmosis in Mice: Comparison of Two Routes of Infection. Parasitology 2005, 131, 303-307. [CrossRef] [PubMed]

64. Murali, A.; Ramlogan-Steel, C.A.; Andrzejewski, S.; Steel, J.C.; Layton, C.J. Retinal Explant Culture: A Platform to Investigate Human Neuro-Retina. Clin. Exp. Ophthalmol. 2019, 47, 274-285. [CrossRef] [PubMed]

65. Caffé, A.R.; Ahuja, P.; Holmqvist, B.; Azadi, S.; Forsell, J.; Holmqvist, I.; Söderpalm, A.K.; van Veen, T. Mouse Retina Explants after Long-Term Culture in Serum Free Medium. J. Chem. Neuroanat. 2002, 22, 263-273. [CrossRef]

66. Amato, R.; Biagioni, M.; Cammalleri, M.; Monte, M.D.; Casini, G. VEGF as a Survival Factor in Ex Vivo Models of Early Diabetic Retinopathy. Investig. Ophthalmol. Vis. Sci. 2016, 57, 3066-3076. [CrossRef] [PubMed]

67. Müller, B. Organotypic Culture of Adult Mouse Retina. In Mouse Cell Culture: Methods and Protocols; Methods in Molecular Biology; Bertoncello, I., Ed.; Springer: New York, NY, USA, 2019; pp. 181-191. [CrossRef] 